\title{
A DINÂMICA DA ARGUMENTAÇÃO SOB UMA PERSPECTIVA LÓGICA*
}

\author{
Frank Thomas Sautter \\ Universidade Federal de Santa Maria/CNPq
}

\begin{abstract}
I used traditional logic to examine some issues of the dynamics of argumentation, such as the possible outcomes of a debate, the influence of strengthening and weakening of propositions on the possible outcomes of a debate, and the influence of inclusion and exclusion of premisses on the possible outcomes of a debate. As the logical square plays an important role in the dynamics of argumentation, I extended it to the classical propositional case.
\end{abstract}

Keywords: Argumentation, dynamics, syllogistic, logical square.

Resumo: Utilizei a lógica tradicional para examinar algumas questões da dinâmica da argumentação, tais como os possíveis desfechos de um debate, a influência do fortalecimento e enfraquecimento de proposições sobre os possíveis resultados de um debate, e a influência da inclusão e supressão de premissas sobre os possíveis resultados de um debate. Como o quadrado lógico desempenha um papel importante na dinâmica da argumentação, eu o estendi para o caso proposicional clássico.

Palavras-chave: Argumentação, dinâmica, silogística, quadrado lógico.

\section{Introdução}

A dinâmica da argumentação difere tanto da estática como da cinemática da argumentação. As questões pelas quais a estática da argumentação se interessa são locais, à medida que não dependem da posição

\footnotetext{
* Agradeço a Rogério Passos Severo pelos comentários a uma versão anterior deste trabalho. Agradeço, também, ao CNPq pelo apoio financeiro ao meu atual projeto de pesquisa.
} 
ocupada pelos argumentos na argumentação; por exemplo, a validade ou invalidade dos argumentos é objeto de avaliação da estática da argumentação. As questões pelas quais a cinemática da argumentação se interessa não são locais no mesmo sentido em que as questões da estática da argumentação são locais, mas são locais à medida que o seu interesse reside na sequência dos argumentos sem, contudo, ter uma preocupação com a contribuição do argumento para a argumentação como um todo. A dinâmica da argumentação não é local nem no sentido em que a estática da argumentação é local, nem no sentido em que a cinemática da argumentação é local; ela se interessa por questões relativas à contribuição de cada argumento à argumentação como um todo, revelando a dependência dos argumentos entre si e a relação deles com as teses centrais em jogo. Assim como um argumento não é um mero conjunto de proposições e nem mesmo uma mera sequência de proposições, mas uma sequência de proposições que exibe uma determinada relação de dependência, uma argumentação não é um mero conjunto de argumentos e nem mesmo uma mera sequência de argumentos, mas uma sequência de argumentos que exibe determinadas relações de dependência.

A despeito de sua ubiquidade e importância em debates reais, questões de dinâmica da argumentação estão notavelmente ausentes nos atuais manuais de lógica. Esse estado de coisas é lamentável, pois tende a reforçar prejuízos contra a lógica formal. Por exemplo, esse estado de coisas tende a reforçar o prejuízo segundo o qual a lógica formal nunca contribui para as questões práticas, ou, menos grave, mas igualmente ruim, o prejuízo segundo o qual o benefício da formalização nunca paga o preço do seu custo.

Neste trabalho procuro responder às seguintes questões pertencentes à dinâmica da argumentação:

- O que se pode esperar, de um ponto de vista estritamente lógico, como o desfecho de um dado debate?

- Como um argumento é afetado pelo fortalecimento ou enfraquecimento de proposições?

- Como um argumento é afetado pela inclusão ou supressão de premissas?

- O que se pode fazer, de um ponto de vista estritamente lógico, em caso de derrota (parcial) em um debate? 
- O que se pode fazer, de um ponto de vista estritamente lógico, em caso de vitória (parcial) em um debate?

Utilizarei, em grande medida, exemplos retirados da silogística aristotélica com pressuposição existencial dos termos. Manuel Correia (2002, p. 101-102) enumera 24 modos conclusivos, que, na mnemotécnica medieval, recebem os seguintes nomes:

- 1ํ. figura: BARBARA e o modo subordinado BARBARI, CELARENT e o modo subordinado CELARONT, DARII e FERIO;

- $2^{\circ}$. figura: CESARE e o modo subordinado CESARO, CAMESTRES

e o modo subordinado CAMESTROS, FESTINO e BAROCO;

- $3^{\circ}$. figura: DARAPTI, FELAPTON, DISAMIS, DATISI, BOCARDO, FERISON;

- 4․ figura: BAMALIP, CALEMES e o modo subordinado CALEMOP, DIMATIS, FESAPO, FRESISON.

É reservado à dinâmica da argumentação um espaço mínimo nos atuais manuais de lógica, uma deferência à sua importância histórica, apesar de suas limitações expressivas. Que uma determinada interpretação da lógica tradicional tenha problemas, não há o que contestar (ver GEACH, 1972). Mas as suas limitações expressivas não são empecilho nem para o exame das principais questões de estática argumentativa, nem para o exame das principais questões de dinâmica argumentativa. Ao contrário, o ambiente limitado da lógica tradicional constitui excelente recurso didático para uma primeira aproximação de tais questões, devido à ausência de distrações.

\section{1 - Os desfechos de um debate}

(...) o conhecimento da Tabela Periódica dos Elementos ou do quadrado das oposições pode ser uma fonte de liberdade e crítica (Ronai Pires da Rocha).

Há uma crença bastante disseminada de que o desfecho natural de um debate é a vitória de uma ala e a derrota da outra, ou seja, a crença de que um debate é, no jargão da Teoria dos Jogos, um jogo de soma zero. De um ponto de vista lógico, isso está longe de ser verdade, pois depende de que teses são defendidas pelas alas em confronto. 
Em rigor, um debate nunca é um jogo de soma zero, pois, se jogado com a motivação correta, todos os seus participantes se beneficiam. John Stuart Mill expressou isso concisa e rigorosamente em "Sobre a Liberdade", de 1854, ao tratar da publicização de opiniões pessoais (e, portanto, do debate que tal publicização pode gerar):

Mas o que há de particularmente mau em silenciar a expressão de uma opinião é o roubo à raça humana - à posteridade, bem como à geração existente, mais aos que discordam de tal opinião do que aos que a mantêm. Se a opinião é correta, privam-nos da oportunidade de trocar o erro pela verdade; se errada, perdem, o que importa em benefício quase tão grande, a percepção mais clara da verdade, produzida por sua colisão com o erro. (MILL, 2000, p. 29)

Em termos estritamente lógicos, quer dizer, em termos dos valores de verdade das teses confrontadas em um debate, há debates que são jogos de soma zero, a saber, aqueles debates em que as teses em confronto são opostas contraditórias, mas também há debates em que as teses em confronto não são opostas contraditórias e, portanto, dependendo do caso, ambas as teses podem ser verdadeiras ou ambas as teses podem ser falsas.

$\mathrm{O}$ quadrado lógico, geralmente apresentado como um assunto que tem um interesse meramente histórico, é uma fonte para a compreensão das distintas possibilidades de desfecho de um debate':

a) Se as teses em confronto são opostas contraditórias, haverá, do ponto de vista lógico, exatamente um vencedor e exatamente um perdedor ${ }^{2}$.

b) Se as teses em confronto são opostas contrárias, haverá, do ponto de vista lógico, no máximo um vencedor, embora ambas as alas possam sair derrotadas ${ }^{3}$.

\footnotetext{
1 As relações de oposição no quadrado lógico, à exceção da relação de oposição contraditória, dependem de pressupostos existenciais dos termos envolvidos. Em rigor, para um purista lógico apenas a relação de oposição contraditória é uma relação lógica.

2 Há três pares de proposições categóricas opostas contraditórias, a saber, "Todo S é P" e "Algum S não é P", "Nenhum S é P" e "Algum S é P", e "Nenhum S é P" e "Algum P é S".

${ }^{3}$ Há dois pares de proposições categóricas opostas contrárias, a saber, "Todo S é P" e "Nenhum S é P", e "Todo S é P" e "Nenhum P é S".
} 
c) Se as teses em confronto são opostas subcontrárias, haverá, do ponto de vista lógico, no mínimo um vencedor, embora ambas as alas possam sair vitoriosas ${ }^{4}$.

d) Se uma tese é oposta subalterna da outra tese em confronto, do ponto de vista lógico aquele que sustenta a tese superalterna não poderá ser o único vencedor ${ }^{5}$.

Uma sistematização similar de relações de oposição pode ser feita em relação, por exemplo, à Lógica Proposicional Clássica. Nas tabelas abaixo estão relacionados todos os quadrados lógicos em que ocorrem os cinco conetivos usuais (negação, conjunção, disjunção inclusiva, condicional material e bicondicional material). Além deles, é necessária a utilização dos seguintes conetivos:

Barra de Sheffer: $\mathrm{p} \uparrow \mathrm{q}={ }_{\text {def }} \neg(\mathrm{p} \wedge \mathrm{q})$

Seta de Peirce: $\mathrm{p} \downarrow \mathrm{q}={ }_{\text {def }} \neg(\mathrm{p} \vee \mathrm{q})$

Disjunção exclusiva: $\mathrm{p} \oplus \mathrm{q}={ }_{\text {def }}(\mathrm{p} \vee \mathrm{q}) \wedge \neg(\mathrm{p} \wedge \mathrm{q})$

Conversa da condicional material: $\mathrm{p} \leftarrow \mathrm{q}={ }_{\text {def }} \mathrm{q} \rightarrow \mathrm{p}$

Além disso, as tabelas devem ser lidas em associação com o quadrado lógico genérico da Figura 1:

Figura 1. Quadrado lógico, onde $\mathrm{P}_{\mathrm{i}}$ é a Posição i.

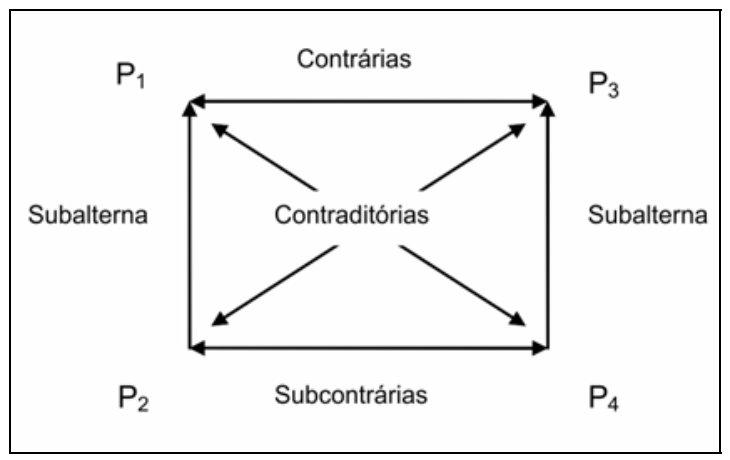

\footnotetext{
${ }^{4}$ Há dois pares de proposições categóricas opostas subcontrárias, a saber, "Algum S é P" e "Algum S não é P", e "Algum P é S" e "Algum S não é P".

${ }^{5}$ Há quatro pares de proposições categóricas subalternas, a saber, "Algum S é P" é subalterna de "Todo S é P", "Algum P é S" é subalterna de "Todo S é P", "Algum S não é P" é subalterna de "Nenhum S é P", e "Algum S não é P" é subalterna de "Nenhum P é S".
} 


\begin{tabular}{|l|l|l|l|}
\hline Posição 1 & Posição 2 & Posição 3 & Posição 4 \\
\hline$p \wedge q$ & $p$ & $\neg p$ & $p \uparrow q$ \\
\hline$p \wedge q$ & $q$ & $\neg q$ & $p \uparrow q$ \\
\hline$p \wedge q$ & $p \leftrightarrow q$ & $p \oplus q$ & $p \uparrow q$ \\
\hline$p \wedge q$ & $p \vee q$ & $p \downarrow q$ & $p \uparrow q$ \\
\hline$p \wedge q$ & $p \leftarrow q$ & $\neg(p \leftarrow q)$ & $p \uparrow q$ \\
\hline$p \wedge q$ & $p \rightarrow q$ & $\neg(p \rightarrow q)$ & $p \uparrow q$ \\
\hline
\end{tabular}

Tabela 1. Quadrado lógico da conjunção

\begin{tabular}{|l|l|l|l|}
\hline Posição 1 & Posição 2 & Posição 3 & Posição 4 \\
\hline$P$ & $p \vee q$ & $p \downarrow q$ & $\neg p$ \\
\hline$Q$ & $p \vee q$ & $p \downarrow q$ & $\neg q$ \\
\hline$p \oplus q$ & $p \vee q$ & $p \downarrow q$ & $p \leftrightarrow q$ \\
\hline$p \wedge q$ & $p \vee q$ & $p \downarrow q$ & $p \uparrow q$ \\
\hline$\neg(p \rightarrow q)$ & $p \vee q$ & $p \downarrow q$ & $p \rightarrow q$ \\
\hline$\neg(p \leftarrow q)$ & $p \vee q$ & $p \downarrow q$ & $p \leftarrow q$ \\
\hline
\end{tabular}

Tabela 2. Quadrado lógico da disjunção inclusiva

\begin{tabular}{|l|l|l|l|}
\hline Posição 1 & Posição 2 & Posição 3 & Posição 4 \\
\hline$\neg p$ & $p \rightarrow q$ & $\neg(p \rightarrow q)$ & $p$ \\
\hline$Q$ & $p \rightarrow q$ & $\neg(p \rightarrow q)$ & $\neg q$ \\
\hline$p \wedge q$ & $p \rightarrow q$ & $\neg(p \rightarrow q)$ & $p \uparrow q$ \\
\hline$p \leftrightarrow q$ & $p \rightarrow q$ & $\neg(p \rightarrow q)$ & $p \oplus q$ \\
\hline$\neg(p \leftarrow q)$ & $p \rightarrow q$ & $\neg(p \rightarrow q)$ & $p \leftarrow q$ \\
\hline$p \downarrow q$ & $p \rightarrow q$ & $\neg(p \rightarrow q)$ & $p \vee q$ \\
\hline
\end{tabular}

Tabela 3. Quadrado lógico da condicional material

\begin{tabular}{|l|l|l|l|}
\hline Posição 1 & Posição 2 & Posição 3 & Posição 4 \\
\hline$p \downarrow q$ & $p \leftrightarrow q$ & $p \oplus q$ & $p \vee q$ \\
\hline$p \wedge q$ & $p \leftrightarrow q$ & $p \oplus q$ & $p \uparrow q$ \\
\hline$p \leftrightarrow q$ & $p \vee q$ & $p \wedge p$ & $p \oplus q$ \\
\hline$p \leftrightarrow q$ & $p \leftarrow q$ & $\neg(p \leftarrow q)$ & $p \oplus q$ \\
\hline$p \leftrightarrow q$ & $p \rightarrow q$ & $\neg(p \rightarrow q)$ & $p \oplus q$ \\
\hline
\end{tabular}

Tabela 4. Quadrado lógico da bicondicional material 


\section{2 - Sobre o fortalecimento e o enfraquecimento de proposições}

Intuitivamente, a proposição $\mathrm{P}$ é mais fraca do que a proposição $\mathrm{Q}$ (a proposição $Q$ é mais forte do que a proposição $P$ ) se e somente se a informação veiculada pela proposição $\mathrm{P}$ é uma parcela própria da informação veiculada pela proposição $\mathrm{Q}$. Formalmente, a proposição $\mathrm{P}$ é mais fraca do que a proposição $Q$ (a proposição $Q$ é mais forte do que a proposição $\mathrm{P}$ ) se e somente se o argumento cuja única premissa é $\mathrm{Q}$ e cuja conclusão é $\mathrm{P}$ é um argumento válido e o argumento cuja única premissa é $\mathrm{P}$ e cuja conclusão é $\mathrm{Q}$ não é válido. Se a proposição $\mathrm{P}$ é mais fraca do que a proposição $\mathrm{Q}$, então $\mathrm{P}$ e Q são comparáveis e distintas quanto à sua força.

$\mathrm{Na}$ silogística aristotélica com pressuposição de existência dos termos há os seguintes pares de proposições comparáveis e distintas quanto à sua força:

a) a proposição "Algum $S$ é $P$ ” é mais fraca do que a proposição "Todo S é P” (por oposição subalterna);

b) a proposição "Algum $P$ é $S$ ” é mais fraca do que a proposição "Todo S é P" (por conversão simples e oposição subalterna);

c) a proposição “Algum $S$ não é P” é mais fraca do que a proposição "Nenhum S é P” (por oposição subalterna);

d) a proposição "Algum P não é S" é mais fraca do que a proposição “Nenhum S é P” (por oposição subalterna e conversão simples).

1. O enfraquecimento de uma premissa de um argumento válido pode afetar a sua validade.

Por exemplo, o enfraquecimento da premissa maior do modo válido BARBARA da $1^{\circ}$. figura resulta no modo inválido IAA da $1^{\circ}$. figura.

Por exemplo, o enfraquecimento da premissa menor do modo válido BARBARI da $1^{\circ}$. figura resulta no modo válido DARII, também da $1^{\circ}$. figura.

2. O enfraquecimento da conclusão de um argumento válido não afeta a sua validade.

Os seguintes pares de modos válidos na mesma figura, em que o segundo modo válido resulta do primeiro modo válido por enfraquecimento da conclusão, atestam certa economia na apresentação da silogística aristotélica com pressuposição existencial dos termos: BARBARA/BARBARI ( $1^{\circ}$. figura), CELARENT/CELARONT (1ํ. figura), CESARE/CESARO ( $2^{\circ}$. figura), CAMESTRES/CAMESTROS ( $2^{\circ}$. figura), CALEMES/CALEMOP ( $4^{\circ}$. 
figura). A adoção desse enfraquecimento da conclusão resulta na apresentação de somente 19 modos válidos "primitivos" e cinco modos válidos derivados.

3. O fortalecimento de uma premissa de um argumento válido não afeta a sua validade.

Os seguintes pares de modos válidos na mesma figura, em que o segundo modo válido resulta do primeiro modo válido por fortalecimento de uma premissa, demonstram que a utilização desse princípio de dinâmica da argumentação pode simplificar enormemente a apresentação da silogística aristotélica com pressuposição existencial dos termos: DARII/BARBARI (1ํㅡ. figura), BAROCO/CAMESTROS ( $2^{\circ}$. figura), FESTINO/CESARO ( $2^{\circ}$. figura), DATISI/DARAPTI ( $3^{\circ}$. figura), DISAMIS/DARAPTI ( $3^{\circ}$. figura),

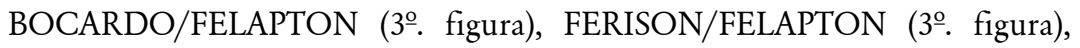
DIMATIS/BAMALIP (4ํ․ figura), FRESISON/FESAPO (4ํ. figura). Nesses caso utilizamos apenas pares comparáveis dos itens a) e c) acima apresentados. A adoção desses itens resulta na apresentação de somente 17 modos válidos "primitivos", e de sete modos válidos derivados.

Se utilizarmos apenas pares comparáveis dos itens b) e d) acima apresentados, os seguintes pares de modos válidos de diferentes figuras, em que o segundo modo válido resulta do primeiro modo válido por fortalecimento de uma premissa, demonstram, novamente, que a utilização desse princípio de dinâmica da argumentação pode simplificar enormemente a apresentação da silogística aristotélica com pressuposição existencial dos termos: FRESISON (4ำ figura) /CELARONT ( $1^{\circ}$. figura), DIMATIS (4ํㅜ. figura) /DARAPTI ( $3^{\circ}$. figura), DARII ( $1^{\circ}$. figura) /DARAPTI ( $3^{\circ}$. figura), FERIO ( $1^{\circ}$. figura) /FELAPTON ( $3^{\circ}$. figura), DISAMIS (3‥ figura) /BAMALIP (4‥ figura), BOCARDO ( $3^{\circ}$. figura) /FESAPO (4ํ. figura), BAROCO ( $2^{\circ}$. figura) /CALEMOP (4ํ․ figura), FESTINO ( $2^{\circ}$. figura) /FESAPO (4ํ. figura). A adoção desses itens resulta na apresentação de somente 18 modos válidos "primitivos", e de seis modos válidos derivados.

Juntos, os quatro itens de fortalecimento de uma premissa acima apresentados resultam numa apresentação econômica da silogística aristotélica com pressuposição existencial dos termos, em que são necessários somente 15 modos válidos "primitivos", a saber, BARBARA, CELARENT, DARII, FERIO, CESARE, CAMESTRES, FESTINO, BAROCO, DISAMIS, DATISI, BOCARDO, FERISON, CALEMES, DIMATIS, FRESISON.

É, no mínimo, curioso que na sistematização da silogística aristotélica com pressuposição existencial dos termos os lógicos medievais tenham 
frequentemente omitido os modos conclusivos resultantes de outros modos conclusivos por enfraquecimento da conclusão $0^{6}$, mas que não tenham feito o mesmo em relação aos modos conclusivos resultantes de outros modos conclusivos por fortalecimento de uma premissa. O fato é surpreendente, porque os princípios que legitimam uma e outra omissão estão interrelacionados. Que havia um interesse da parte de lógicos medievais nos aspectos dinâmicos da argumentação o atesta a prática popular das obligationes (DUTILH NOVAES, 2007). Talvez o que possa explicar essa assimetria no tratamento do enfraquecimento da conclusão em relação ao fortalecimento de premissa seja a ausência de um tratamento sistemático meticuloso da dinâmica da argumentação per se.

4. O fortalecimento da conclusão de um argumento válido pode afetar a sua validade.

Por exemplo, o fortalecimento da conclusão do modo válido DARII da $1^{\circ}$. figura resulta no modo inválido AIA da $1^{\circ}$. figura.

Por exemplo, o fortalecimento da conclusão do modo válido BARBARI da $1^{\circ}$. figura resulta no modo válido BARBARA, também da $1^{\circ}$. figura.

\section{3 - Sobre derrotas e vitórias em debates}

Na Seção 1 vimos como diferentes tipos de oposição entre as teses em confronto podem, sob a perspectiva lógica, guiar nossas expectativas em relação aos diferentes desfechos de um debate, e na Seção 2 vimos como o fortalecimento e o enfraquecimento de proposições pode afetar a validade e a invalidade de argumentos. Juntos, formas de oposição e força relativa de proposições, nos ajudam a entender o que é possível fazer frente a uma derrota num debate e frente a uma vitória num debate.

Do mesmo modo que há uma crença bastante disseminada que o desfecho natural de um debate é a vitória de uma das partes envolvidas e a derrota da outra, também há uma crença bastante disseminada (e pelas mesmas razões) de que não há nada a fazer frente a uma derrota, ou seja, não há nada a fazer se a nossa tese se mostra falsa. Similarmente, há a crença de que nada é preciso fazer ou pode ser feito no caso de uma vitória, ou seja, no caso em que a nossa tese se mostra verdadeira.

${ }^{6}$ Correia (2002, p. 101) os denomina "modos subordinados" mas, também, "modos irrelevantes". 
Se algo se pode fazer em caso de derrota ou de vitória dependerá, novamente, do tipo de oposição que se estabelece entre as teses em confronto. O caso clássico é aquele em que as teses em confronto são opostas contraditórias; nesses casos não há, de fato, nada a fazer: uma derrota é uma derrota total. Mas, se as teses não são opostas contraditórias, sempre é possível enfraquecer a tese derrotada e manter-se em oposição com o adversário. $\mathrm{Na}$ silogística aristotélica com pressuposição existencial dos termos isso se dá em dois casos:

a) A tese derrotada é da forma "Nenhum S é P" (“Nenhum P é S") e a outra tese é "Todo S é P". Nesse caso o enfraquecimento "Algum $S$ não é P" da tese derrotada ainda se mantém em oposição com a tese "Todo $S$ é P” e o debate pode prosseguir em níveis mais modestos para aquele cuja tese original foi derrotada.

b) A tese derrotada é da forma "Todo S é P" e a outra tese é "Nenhum $S$ é P" ("Nenhum P é S"). Nesse caso o enfraquecimento "Algum S é P" (“Algum P é $S$ ”) da tese derrotada ainda se mantém em oposição com a tese "Nenhum S é P” (“Nenhum P é S") e o debate pode prosseguir em níveis mais modestos para aquele cuja tese original foi derrotada.

Mas também pode acontecer que aquele cuja tese saiu-se vitoriosa, no sentido de se mostrar verdadeira, queira continuar o debate, agora com uma tese ainda mais forte. $\mathrm{Na}$ silogística aristotélica com pressuposição existencial dos termos isso se dá em quatro casos:

a) A tese vitoriosa é "Algum S é P" (“Algum P é S”) e a outra tese é “Algum $S$ não é P". Nesse caso o fortalecimento "Todo $S$ é P” da tese vitoriosa conduz o debate a um nível mais ambicioso para aquele cuja tese original saiu-se vitoriosa.

b) A tese vitoriosa é "Algum S é P” (“Algum P é S”) e a outra tese é "Nenhum S é P" ("Nenhum P é S"). Nesse caso o fortalecimento "Todo S é $\mathrm{P}$ ” (“Todo $\mathrm{P}$ é $\mathrm{S}$ ”) da tese vitoriosa também conduz o debate a um nível mais ambicioso para aquele cuja tese original saiu-se vitoriosa.

c) A tese vitoriosa é "Algum S não é P" e a outra tese é "Algum S é P" (“Algum P é S"). Nesse caso o fortalecimento "Nenhum S é P” ("Nenhum P é $S$ ”) da tese vitoriosa também conduz o debate a um nível mais ambicioso para aquele cuja tese original saiu-se vitoriosa.

d) A tese vitoriosa é "Algum $S$ não é P" e a outra tese é "Todo $S$ é P". Nesse caso o fortalecimento "Nenhum S é P" ("Nenhum P é S") da tese 
vitoriosa também conduz o debate a um nível mais ambicioso para aquele cuja tese original saiu-se vitoriosa.

Desde que também é possível obter quadrados lógicos para os conetivos proposicionais (ver Seção 1), o leitor pode facilmente perceber a riqueza desse jogo de derrotas e vitórias parciais.

\section{4 - Sobre a inclusão e supressão de premissas}

Há, quanto à inclusão e a supressão de premissas em um argumento, quatro princípios clássicos:

1. A inclusão de premissa em um argumento válido não afeta sua validade.

2. A inclusão de premissa em um argumento inválido pode afetar sua validade.

3. A supressão de premissa de um argumento válido pode afetar sua validade.

4. A supressão de premissa de um argumento inválido não afeta sua invalidade.

Aqui, é claro, a silogística não nos pode auxiliar com exemplos. A razão para isso é que os silogismos válidos possuem uma virtude epistêmica não encontrada geralmente nos argumentos válidos: num silogismo válido não há premissas desnecessárias, ou seja, cada uma das premissas - maior e menor - contribui para a conclusão. A definição aristotélica de silogismo (válido), nos Analíticos Anteriores, já incorpora condições epistêmicas ao solicitar que a conclusão seja distinta das premissas, ou seja, uma petição de princípio não é, por definição, um argumento válido à luz da proposta aristotélica. Contudo, longe de jogar contra a silogística aristotélica, essa falta de exemplos relacionados aos quatro princípios clássicos acima apresentados joga, a meu ver, a favor dela: quem sabe precisemos rever o nosso conceito de argumento e excluir da classe de argumentos em sentido forte aqueles em que há premissas espúrias, ou nos quais a conclusão meramente repete a premissa, ou, inclusive, em que as premissas formam um conjunto inconsistente de proposições. Isso, talvez, nos poupasse de uma série de discussões de importância duvidosa na filosofia da lógica. 


\section{5 - 0 que é, afinal, um debate?}

Ao longo deste trabalho estivemos utilizando a noção de debate, sem contudo caracterizá-la. Isso foi proposital: nosso principal interesse estava na dinâmica da argumentação, e uma noção precisa de debate não era essencial. A verdade é que a noção de debate é uma noção complexa e elusiva de uma perspectiva lógica, e um excesso de pudor, exigindo sua caracterização precisa, somente nos distrairia de nosso objetivo principal. Mas, agora, vamos enfrentar a questão, ao menos naquilo que compete à lógica.

Sustento que a noção de debate é, em última instância, logicamente inefável. A razão subjacente a essa tese é simples: um debate apresenta uma unidade temática e a lógica não tem recursos para dizer quando um conjunto de proposições diz respeito ao mesmo assunto.

O que se pode fazer, sob uma perspectiva lógica, é modelar o melhor possível um dado debate. Isso envolve os seguintes elementos:

a) Um conjunto $\Gamma$ de proposições que são as teses compartilhadas pelas partes do debate. Essa lição advém da retórica e é, com inteira justiça, enfatizada pelos defensores da lógica informal: sem um conjunto de teses compartilhadas não é possível debate algum. Para que um debate seja um debate genuíno, parece razoável impor que $\Gamma$ constitua um conjunto consistente de proposições.

b) As teses das partes do debate - denominemo-las essas partes do debate de "proponente" e "oponente" - são independentes de $\Gamma$, ou seja, se $\alpha$ é a tese do proponente e $\beta$ é a tese do oponente, $\alpha, \neg \alpha, \beta$ e $\neg \beta$ são teses consistentes com $\Gamma$.

c) As teses do proponente e do oponente estão em oposição, mesmo que não seja uma oposição contraditória. Isso pode ser modelado através da seguinte condição: $\neg \beta$ é consistente com $\Gamma \cup\{\alpha\}$ ou $\neg \alpha$ é consistente com $\Gamma \cup\{\beta\}$.

\section{6 - Considerações finais}

Se há aqueles que pecam pelo excesso, por crerem que a lógica formal é uma panaceia filosófica; também há aqueles que pecam pela falta, por crerem que a lógica formal é um mero exercício intelectual, para a qual os problemas filosóficos são inexpugnáveis. A verdade, como em geral ocorre, está no meio termo. 
Os prejuízos contra a lógica formal são, em parte, devidos à falta de esforço na modelagem de situações reais, importantes. Um lógico não é semelhante a um matemático teórico, cuja pesquisa pode esperar a posteridade para mostrar o seu valor; o lógico assemelha-se mais ao matemático aplicado. A lógica prepara o terreno para a atividade urgente de comunhão de ideias; para utilizar uma feliz expressão de um colega de profissão: a lógica é o chão da liberdade.

\section{Referências}

CORREIA, M. La lógica de Aristóteles: Lecciones sobre el origem del pensamiento lógico en la antigüedad. Santiago: Ediciones Universidad Católica de Chile, 2002.

DUTILH, N. C. Formalizing Medieval Logical Theories: Suppositio, Consequentiae and Obligationes. Logic, Epistemology, and the Unity of Science 7. Dordrecht: Springer, 2007.

GEACH, P. T. "History of the Corruptions of Logic: An Inaugural Lecture 1968". In: . Logic matters. Oxford: Basil Blackwell, 1972. p. 44-61.

MILL, J. S. A liberdade; Utilitarismo. São Paulo: Martins Fontes, 2000. 